\title{
Global transcriptome analysis of Stenotrophomonas maltophilia in response to growth at human body temperature
}

\author{
Prashant P. Patil†, Sanjeet Kumar†, Amandeep Kaur, Samriti Midhał, Kanika Bansal and Prabhu B. Pati**
}

\begin{abstract}
Stenotrophomonas maltophilia is a typical example of an environmental originated opportunistic human pathogen, which can thrive at different habitats including the human body and can cause a wide range of infections. It must cope with heat stress during transition from the environment to the human body as the physiological temperature of the human body $\left(37^{\circ} \mathrm{C}\right)$ is higher than environmental niches $\left(22-30^{\circ} \mathrm{C}\right)$. Interestingly, S. rhizophila a phylogenetic neighbour of S. maltophilia within genus Stenotrophomonas is unable to grow at $37^{\circ} \mathrm{C}$. Thus, it is crucial to understand how S. maltophilia is adapted to human body temperature, which could suggest its evolution as an opportunistic human pathogen. In this study, we have performed comparative transcriptome analysis of S. maltophilia grown at 28 and $37^{\circ} \mathrm{C}$ as temperature representative for environmental niches and the human body, respectively. RNA-Seq analysis revealed several interesting findings showing alterations in gene-expression levels at 28 and $37^{\circ} \mathrm{C}$, which can play an important role during infection. We have observed downregulation of genes involved in cellular motility, energy production and metabolism, replication and repair whereas upregulation of VirB/D4 type IV secretion system, aerotaxis, cation diffusion facilitator family transporter and Lacl family transcriptional regulators at $37^{\circ} \mathrm{C}$. Microscopy and plate assays corroborated altered expression of genes involved in motility. The results obtained enhance our understanding of the strategies employed by S. maltophilia during adaptation towards the human body.
\end{abstract}

\section{DATA SUMMARY}

(1) Data file (.txt) for all replicates of two conditions i.e. three replicates at $28^{\circ} \mathrm{C}$ and three replicates at $37^{\circ} \mathrm{C}$, used to generate the volcano plot obtained from the differential expression analysis (https://doi.org/10.6084/ m9.figshare.14370461).

(2) Data file (.xlsx) used to generate the bar graph plot for the number of differentially expressed genes and number of CDS (https://doi.org/10.6084/m9.figshare. 14370467).

(3) Data file (.xlsx) used for plotting the qRT-PCR bar graph for validation of the differentially expressed genes (https://doi.org/10.6084/m9.figshare.14375624).

(4) Data file (.xlsx) used for generating presence or absence heatmap of differentially expressed genes across the strains of Stenotrophomonas maltophilia complex (https://doi.org/10.6084/m9.figshare.14370470).
(5) Mapped reads for both conditions, i.e. at 28 and $37^{\circ} \mathrm{C}\left(\_1, \_2\right.$, and $\_3$ represent the three replicates for each conditions) (https://doi.org/10.6084/m9.figshare. 14370458).

\section{INTRODUCTION}

Variation in temperature is one of the most crucial stress factors for pathogens of environmental origin during adaptation to the human body, as temperature of the external biosphere is generally $22-30{ }^{\circ} \mathrm{C}$. There are different molecular mechanisms by which bacteria sense and respond to changes in temperature. Moreover, temperature is one of the critical signals that influences the different bacterial processes. In bacterial pathogens of mammals including Shigella, Yersinia, Pseudomonas etc., the body temperature of the host, i.e. $37^{\circ} \mathrm{C}$ induces the expression of virulence

Received 12 January 2021; Accepted 04 May 2021; Published 12 July 2021

Author affiliations: 'Bacterial Genomics and Evolution Laboratory, CSIR-Institute of Microbial Technology, Chandigarh, India.

*Correspondence: Prabhu B. Patil, pbpatil@imtech.res.in

Keywords: RNA-Seq; Stenotrophomonas maltophilia; thermoregulation; transcriptome.

Abbreviations: BAM, binary version of SAM; CDF, cation diffusion facilitator; FPKM, fragments per kilobase of transcript per million mapped reads;

PAMP, pathogen associated molecular pattern; qRT-PCR, real time quantitative reverse transcription PCR; SAM, sequence alignment map; Smc,

Stenotrophomonas maltophilia complex; T4SS, type IV secretion system; UTR, untranslated region.

$\ddagger$ Present address: Institute of Infection, Veterinary and Ecological Sciences, University of Liverpool, Liverpool, UK.

Gene Expression Omnibus database (accession number: GSE101926).

†These authors contributed equally to this work

$000600 \odot 2021$ The Authors 
factors $[1,2]$. Temperature is one of the important signals that a mammalian pathogen uses to regulate the virulence trait once it has entered its warm-blooded host [3]. In contrast, in pathogens of plants and ectothermic hosts such as fish, molluscs and amphibians, virulence gene expression is elevated at the lower temperatures, suggesting a role of temperature in the coordination of bacterial pathogenesis and virulence $[4,5]$. Recently discovered RNA thermometers are an interesting tool in bacteria for responding to such external temperature stresses. They are RNA structures formed at the 5' UTR regions of transcripts specifying regulatory proteins responsible for expression of virulenceassociated traits, which blocks translation initiation of genes at non-permissive temperatures [6].

Genus Stenotrophomonas comprises several species from a diverse range of niches such as S. lactitubi and S. indicatrix from food [7], S. bentonitica [8] and S. chelatiphaga from soil etc. [9-11]. S. maltophilia is a ubiquitous bacterium, which has emerged as a multidrug-resistant global opportunistic pathogen in immunocompromised patients [12-14]. S. maltophilia is a versatile bacterium, which adapts to a wide range of environments and it is the only validated species among Stenotrophomonas genus, which causes human- and animal-associated infections $[9,15]$. Apart from this detrimental effect, S. maltophilia has an extraordinary range of activities such as plant growth promotion, degradation of anthropogenic pollutants and production of biomolecules $[15,16]$. Presence of such a wide range of properties makes this bacterium an important biotechnological candidate, but the pathogenic potential of this bacterium limits its use for biotechnological applications [16]. The comparison of the S. maltophilia with S. rhizophila, a non-pathogenic and phylogenetically related species, revealed that $S$. rhizophila lacks crucial virulence factors and heat-shock proteins [17]. S. rhizophila is unable to grow at human body temperature, $37^{\circ} \mathrm{C}$ due to the absence of heat-shock genes and upregulation of genes involved in suicidal mechanisms [17]. Thus, it is essential to understand the adaptation of rapidly emerging multidrug-resistance opportunistic pathogen S. maltophilia to human body temperature, which is considered as the first step towards transition from environment to the human body.

Advances in high-throughput sequencing approaches will accurately quantify levels of expression of mRNA (RNASeq) thus, providing significant advances over microarrays [18-20]. To understand the genetic response, mechanistic basis and factors involved in the successful adaptation of the S. maltophilia at human body temperature, we systematically examined the transcriptome during the growth at 28 and $37^{\circ} \mathrm{C}$ using RNA-Seq experiments.

\section{METHODS}

\section{Bacterial strain and growth condition}

S. maltophilia strain MTCC $434^{\mathrm{T}}$, which is isogenic with the ATCC $13637^{\mathrm{T}}$ was used in all experiments. S. maltophilia

\section{Impact Statement}

Stenotrophomonas maltophilia is a WHO listed multidrugresistant nosocomial pathogen. Interestingly, S. maltophilia species can grow both at 28 and $37{ }^{\circ} \mathrm{C}$ unlike its closest taxonomic relative, i.e. S. rhizophila and also the majority species belonging to this genus. Hence this ability to grow at $37{ }^{\circ} \mathrm{C}$, i.e. human body temperature might have played a key role in the unique success and emergence of this species as an opportunistic human pathogen. Using transcriptome sequencing, we have identified a set of genes, which are differentially regulated at $37^{\circ} \mathrm{C}$, and investigated their evolutionary history. This study has revealed regulation of genes involved in motility, metabolism, energy, replication, transcription, aerotaxis and a type IV secretion system might have a role in successful adaption to a distinct lifestyle. The findings will be helpful in further systematic studies on understanding and management of an emerging human pathogen such as S. maltophilia.

ATCC $13637^{\mathrm{T}}$ was grown in Luria-Bertani Miller Broth with shaking at 200 r.p.m. at either 37 or $28^{\circ} \mathrm{C}$.

\section{Total RNA extraction, quantification and Integrity estimation}

S. maltophilia ATCC $13637^{\mathrm{T}}$ was grown in $20 \mathrm{ml}$ Luria-Bertani Broth, Miller in $100 \mathrm{ml}$ Erlenmeyer flask at 37 and $28^{\circ} \mathrm{C}$ under constant agitation at 200 r.p.m. Samples were withdrawn at intervals for optical density monitoring at $600 \mathrm{~nm}\left(\mathrm{OD}_{600}\right)$, and cells from both cultures were harvested at mid-log phase $\left(\mathrm{OD}_{600}=0.8\right.$ to 1$)$ by centrifugation at 6000 r.p.m. at for $10 \mathrm{~min}$ at $4{ }^{\circ} \mathrm{C}$ and immediately frozen at $-80^{\circ} \mathrm{C}$ or proceeded to the RNA isolation. For isolation of RNA, the pellet was resuspended in the $1 \mathrm{ml}$ of TRIzol (Invitrogen, Carlsbad, CA, USA) and dissolved by vigorous mixing. The supernatant was transferred into a clean tube, which contained one volume of $100 \%$ ethanol mixed by repeated gentle inversion. The RNA was purified and treated with DNase by using the Direct-zol RNA MiniPrep kit (Zymo Research Corporation, Orange, CA, USA), according to the manufacturer's recommendation. The purity of isolated total RNA, was determined by using the NanoDrop (Thermo Scientific, Wilmington, DE, USA) and quantified by using Qubit (Invitrogen, Carlsbad, CA, USA). Agilent Bioanalyzer with Agilent RNA 6000 Nano Kit (Agilent Technologies, Palo Alto, CA, USA) was used as per manufacturer's guidelines to assess the integrity of RNA samples. The RNA samples with RNA Integrity Number (RIN) $>8$ were selected for cDNA synthesis and subsequent Illumina library construction .

\section{Ribosomal RNA depletion, cDNA library preparation and Illumina sequencing}

The ScriptSeq complete kit (Epicentre, Illumina, Madison, WI, USA), a combined kit for the ribosomal (rRNA) depletion 
Table 1. List of primers used in qRT-PCR for validation of RNA-Seq

\begin{tabular}{|c|c|c|}
\hline S. no. & Gene & Primer sequence $\left(5^{\prime}-3^{\prime}\right)$ \\
\hline \multirow[t]{2}{*}{1} & SM-ftsZ-F & GGCGCATTTTGAACTGATCG \\
\hline & SM-ftsZ-R & AGCTTGGCACCGCAATTCT \\
\hline \multirow[t]{2}{*}{2} & SM-fimA-F & TGCCGACCGTGTCCAAGAA \\
\hline & SM-fimA-R & GCACTTGGTCAGGTTGATGG \\
\hline \multirow[t]{2}{*}{3} & SM-fimB-F & ACTCTGGCCGAAGTACATGC \\
\hline & SM-fimB-R & GCCGTAGTCGTTGATGGTGATGAA \\
\hline \multirow[t]{2}{*}{4} & SM-16s-F & GACCTTGCGCGATTGAATG \\
\hline & SM-16s-R & CGGATCGTCGCCTTGGT \\
\hline \multirow[t]{2}{*}{5} & SM-virB1-F & GTCAGGGTCGAACATCATCC \\
\hline & SM-virB1-R & GATGGGTAAACGGTGTAGGC \\
\hline \multirow[t]{2}{*}{6} & SM-virB4-F & TGTGATGGACGAATTCTGGA \\
\hline & SM-virB4-R & ATCACTCTTCAGCGCGTCTT \\
\hline \multirow[t]{2}{*}{7} & SM-virB6-F & GTGCGATGCTGATGCTGTAT \\
\hline & SM-virB6-R & AATGCCGTAGAACAGCCAAC \\
\hline \multirow[t]{2}{*}{8} & SM-virB11-F & CGCGAGTACGCAGAGTTCTT \\
\hline & SM-virB11-R & TCGTTGTCCGGGATATGATT \\
\hline \multirow[t]{2}{*}{9} & SM-trbJ-F & CATGACATCCCGAAATCACA \\
\hline & SM-trbJ-R & GGTCGAAGACAGGGTAACCA \\
\hline \multirow[t]{2}{*}{10} & SM-MMT12-F & CATCGAAATCCATGTGCTGA \\
\hline & SM-MMT12-R & AATCGATGGTCAGCCAGAAC \\
\hline \multirow[t]{2}{*}{11} & SM-yehB-F & CAGTTCAACTCCAGCTTCCTG \\
\hline & SM-yehB-R & ACGTACACGTCGACACGATAGTT \\
\hline \multirow[t]{2}{*}{12} & SM-fruR-F & GATTGTCGAGTACCACGCTGT \\
\hline & SM-fruR-R & CACTGTATCTGCAATTGATGCAC \\
\hline \multirow[t]{2}{*}{13} & SM-aer-F & GTATACAAGGACATGTGGGACACC \\
\hline & SM-aer-R & GATGCTGATGTAGGAGGTGATGT \\
\hline \multirow[t]{2}{*}{14} & SM-cspA2-F & GGACCTGTTTGTGCACTTCC \\
\hline & SM-cspA2-R & GTCAGCCTGCATACCCTTCT \\
\hline
\end{tabular}

Ribo-Zero Kit (Bacteria) (Epicentre, Illumina, Madison, WI, USA) and cDNA library construction kit, ScriptSeq v2 RNASeq library preparation kit (Epicentre, Illumina, Madison, WI, USA) was used for this purpose. A total of $5 \mu \mathrm{g}$ of RNA was used for rRNA depletion by using Ribo-Zero (Epicentre, Illumina, Madison, WI, USA) kit and purified by using Qiagen-RNeasy miniElute (Qiagen GmbH, Hilden, Germany) Clean-up kit. The Ribo-Zero treated RNA was quantified by using Agilent Bioanalyzer RNA 6000 Pico Kit (Agilent Technologies, CA, USA) and further used for the cDNA synthesis by using ScriptSeq v2 RNA-Seq kit (Epicentre, Illumina, Madison, WI, USA). The cDNA was purified using AMPure XP (Beckman Coulter, Brea, CA, USA) beads and multiplexed by using ScriptSeq Index PCR Primers (Epicentre, Illumina, Madison, WI, USA). cDNA libraries were quantified by using KAPA Illumina Library Quantification kit (KAPA Biosystems, Wilmington, MA, USA). Finally, six libraries, which contain the biological triplicate of S. maltophilia ATCC $13637^{\mathrm{T}}$ cultured at $28^{\circ} \mathrm{C}$ (SM_28_R1, SM_28_R2, SM_28_R3) and $37^{\circ} \mathrm{C}$ (SM_37_R1, SM_37_R2, SM_37_R3) were pooled and sequenced using in-house Illumina MiSeq (Illumina, San Diego, CA, USA) platform with $2 \times 75$ bp paired end run.

\section{RNA-Seq data analysis}

The indexing adapters were trimmed by MiSeq control software during the base calling and read quality assessment was done using FastQC v0.11.2 [21]. The complete genome sequences of S. maltophilia ATCC $13637^{\mathrm{T}}$ (accession no.: NZ CP008838) was downloaded from NCBI-GenBank (https:// www.ncbi.nlm.nih.gov/genome/880?genome_assembly_id= 205295) and used as a reference for aligning the reads by using Bowtie2 [22]. The aligned SAM files generated by bowtie were sorted using samtools v1.4.1 [23]. The obtained BAM files were used as input to cufflinks v2.2.1 $[19,24,25]$, which was used to assemble transcripts with FPKM (fragments per kilobase of transcript per million mapped reads) values. The data files for the replicates were merged into single transcript with Cuffmerge and differential gene expression analysis between both conditions, i.e. 28 and $37^{\circ} \mathrm{C}$ was performed using the Cuffdiff, a package of the cufflinks v2.2.1 $[19,24,25]$. The output data from Cuffdiff were imported to cummeRbund v2.32 [26], which is based on $R$ statistical package version 3.4.0 for visualization. Gene-expression data were deposited to the Gene Expression Omnibus database (accession number: GSE101926).

\section{qRT-PCR validation of the differentially expressed genes}

To confirm some of the differential expressed genes obtained using RNA-Seq, a conventional real-time quantitative reverse transcription-PCR (qRT-PCR) was employed to measure changes in the mRNA level of each gene. Gene-specific primers of the differentially expressed genes were designed by using primer3 tool (http://bioinfo.ut.ee/primer3-0.4.0/) and listed in Table 1. RNA was isolated from bacterial cells grown at 28 and $37^{\circ} \mathrm{C}$ as described earlier. The quantitative real-time PCR assay was performed with SuperScript III Platinum SYBR Green One-Step qRT-PCR kit (Thermo Scientific, Wilmington, DE, USA). For each sample, three technical replicates were included, and reactions were set up according to the manufacturer's guidelines. The amplification conditions were as follows: cDNA synthesis $50{ }^{\circ} \mathrm{C}$ for $45 \mathrm{~min}$, initial denaturation at $95^{\circ} \mathrm{C}$ for $5 \mathrm{~min}, 40$ cycles of denaturation at $95{ }^{\circ} \mathrm{C}$ for $15 \mathrm{~s}$ followed by annealing at $60{ }^{\circ} \mathrm{C}$ for $30 \mathrm{~s}$ and extension at $40^{\circ} \mathrm{C}$ for $30 \mathrm{~s}$. Melting curve analysis confirmed that all PCRs amplified a single product. Gene-expression levels were normalized to 16S rRNA gene and $f t s Z$ gene. The relative expression of each gene at $37^{\circ} \mathrm{C}$ relative to $28^{\circ} \mathrm{C}$ was expressed as fold change calculated by using $2^{-\Delta \Delta c t}$ method. The resulting fold-change values were 
converted to $\log _{2}$-fold value and were plotted against the $\log _{2}$ fold of RNA-Seq data.

\section{Functional categorization of differentially expressed genes}

EggNOG v4.5.1, a database [27] of orthologous groups and functional annotation was used to classify genes differentially expressed at 28 and $37^{\circ} \mathrm{C}$ into functional categories based on Clusters of Orthologous Groups (COG).

All the full-length differentially expressed genes obtained from the RNA-Seq experiment were fetched from all the type strains of genus Stenotrophomonas maltophilia complex (Smc) using tBLASTn [28]. Cut-off for similarity was set to be $60 \%$ and coverage was $50 \%$. All the differentially expressed genes from reference genome ATCC $13637^{\mathrm{T}}$ were annotated using eggNOG-mapper v2 [27]. Based on the presence and absence of the gene a heatmap was constructed using GENEEv3.0.215 (https://software.broadinstitute.org/GENE-E/).

\section{Transmission electron microscopy}

Transmission electron microscopy was used to visualize the morphology of the flagella at 28 and $37^{\circ} \mathrm{C}$. Bacterial cultures were grown in $20 \mathrm{ml} \mathrm{LB}$ and incubated at 28 and $37^{\circ} \mathrm{C}$, respectively, until OD600nm reaches 0.8 . The cells were harvested by centrifugation at 2000 r.p.m. for $10 \mathrm{~min}$. The cell pellet was washed twice with 1X PBS (Invitrogen, Carlsbad, CA, USA) and finally suspended in $50 \mu \mathrm{l}$ of $1 \mathrm{X}$ PBS (Invitrogen, Carlsbad, CA, USA). Altogether, 10-20 $\mu$ l of bacterial suspension was placed on a carbon-coated copper grid (300 mesh, Nisshin EM) for $15 \mathrm{~min}$. The grid was then negatively stained for $30 \mathrm{~s}$ with $2 \%$ phosphotungstic acid, dried and examined using JEM 2100 transmission electron microscope (JEOL, Tokyo, Japan) operating at $200 \mathrm{kV}$.

\section{Motility assays}

Motility patterns of Stenotrophomonas maltophilia ATCC $13637^{\mathrm{T}}$ were assessed by using motility media. For swimming motility, $5 \mu \mathrm{l}$ of overnight grown culture was spotted on plates containing $1 \%$ tryptone, $0.5 \% \mathrm{NaCl}$ and $0.3 \%$ agar. Similarly, for swarming motility $5 \mu$ of overnight grown culture was spotted on plates containing $1 \%$ tryptone, $0.5 \% \mathrm{NaCl}$ and $0.5 \%$ agar. Plates were incubated at 28 and $37^{\circ} \mathrm{C}$ for 7 days. Twitching motility was evaluated on plates containing $1 \%$ tryptone, $0.5 \% \mathrm{NaCl}$ and $1.2 \%$ agar. A bacterial colony was stabbed deep into the agar to the bottom with the help of a sterile toothpick. Plates were incubated at 28 and $37^{\circ} \mathrm{C}$ for 7 days. Then, to check twitching motility, agar was removed, and plates were stained with $0.1 \%$ crystal violet. Motility assays were carried out on three biological replicates.

\section{Growth curve measurements}

The growth curves at two temperatures, i.e. 28 and $37^{\circ} \mathrm{C}$ was generated by growing bacterial culture at 28 and $37^{\circ} \mathrm{C}$ overnight. Then, $1 \%$ of the overnight grown culture $(\mathrm{OD}=1.0)$ was then inoculated in fresh $50 \mathrm{ml} \mathrm{LB}$ with an initial $\mathrm{OD}_{600} \mathrm{~nm}$ 0.015 . Readings were taken every $1 \mathrm{~h}$ for $32 \mathrm{~h}$ at $\mathrm{OD}_{600} \mathrm{~nm}$.
Table 2. Summary of Illumina RNA-Seq data generated. S. maltophilia ATCC $13637^{\top}$ grown at 28 (SM_28) and $37^{\circ} \mathrm{C}$ (SM_37) number (_1,_2,_3) following SM_28 and SM_37 represents replicates for each condition

\begin{tabular}{|lccc|}
\hline & $\begin{array}{c}\text { Total quality } \\
\text { reads }\end{array}$ & $\begin{array}{c}\text { Total mapped } \\
\text { reads }\end{array}$ & $\begin{array}{c}\text { Overall mapping } \\
\text { percentage }\end{array}$ \\
\hline SM_28_R1 & 9353340 & 8806943 & $94.16 \%$ \\
SM_28_R2 & 18954226 & 17559441 & $92.64 \%$ \\
SM_28_R3 & 15978000 & 14037770 & $87.86 \%$ \\
SM_37_R1 & 7072156 & 6782141 & $95.90 \%$ \\
SM_37_R2 & 22620470 & 22620470 & $93.65 \%$ \\
SM_37_R3 & 28483870 & 28483870 & $94.74 \%$ \\
\hline
\end{tabular}

\section{RESULTS AND DISCUSSION \\ Comparative transcriptome analyses of S. maltophilia during growth at 28 and $37^{\circ} \mathrm{C}$}

To determine the genetic mechanism underlying adaptation of S. maltophilia at human body temperature, we performed RNA-Seq analysis on three biological replicates of $S$. maltophilia grown at 28 and $37^{\circ} \mathrm{C}$.

A total 4676670, 9477113, 7989000 and 3536078, 11310235 and 14241935 paired-end sequencing reads were obtained for three biological replicates for growth at $28{ }^{\circ} \mathrm{C}$ (SM_28_R1, SM_28_R2, SM_28_R3) and $37^{\circ} \mathrm{C}$ (SM_37_R1, SM_37_R2, SM_37_R3), respectively. Reads from all replicates were mapped to the reference genome S. maltophilia ATCC $13637^{\mathrm{T}}$ with overall mapping frequency ranging from $87-94 \%$ (Table 2).

To identify differentially expressed genes at $37{ }^{\circ} \mathrm{C}$, we compared transcript profiles of S. maltophilia ATCC $13637^{\mathrm{T}}$ grown at 28 and $37^{\circ} \mathrm{C}$. The global transcriptional profiles for two conditions were obtained by data normalization and statistical analysis. A matrix of pairwise comparison based on the FPKM values between two conditions was obtained. It was used to generate the volcano plot (Fig. 1a) to map the fold change in transcript expression against its statistical significance ( $q$-values).

Total 81 gene were differentially expressed when the S. maltophilia ATCC $13637^{\mathrm{T}}$ was grown at $37^{\circ} \mathrm{C}$ as compared to growth at $28^{\circ} \mathrm{C}$ with the statistically significant cut-off values: $q$-value $<0.05$ and $\log _{2}$-fold change $>2$. Also, all the hypothetical and ribosomal genes were removed from the list of differentially expressed genes. Among differentially expressed genes, 12 genes (accounting for the $15 \%$ of differentially expressed genes) were upregulated (Table 3 ) while 69 genes (accounting for $85 \%$ ) were downregulated at 37 ${ }^{\circ} \mathrm{C}$ as compared to the $28^{\circ} \mathrm{C}$ (Table 4). The classification of differentially expressed genes by COG revealed that genes in 16 COG classes were differentially expressed (Fig. 1b). The most COG categories for which the greater number of the genes were differentially expressed are intracellular trafficking and secretion, signal transduction, cell motility and with unknown function (Fig. 1b). The differentially 


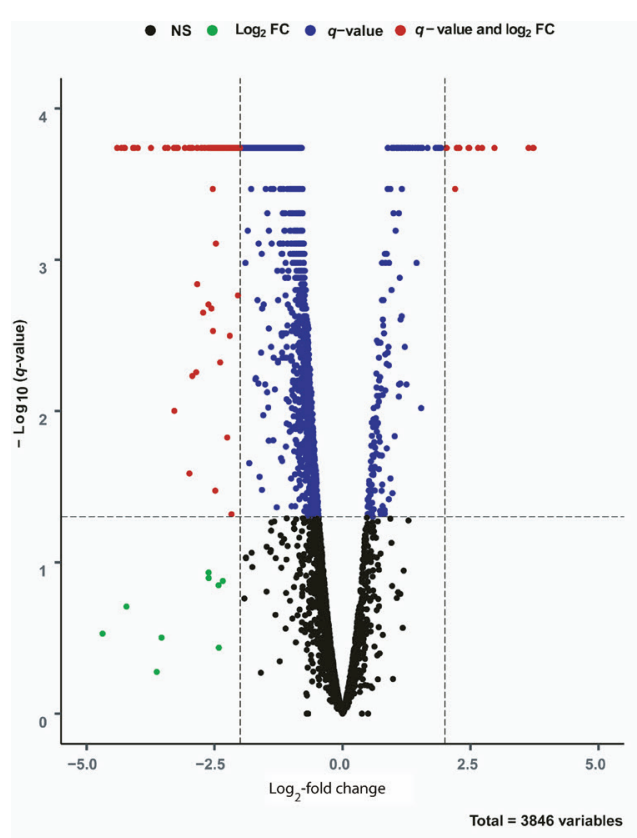

(A)

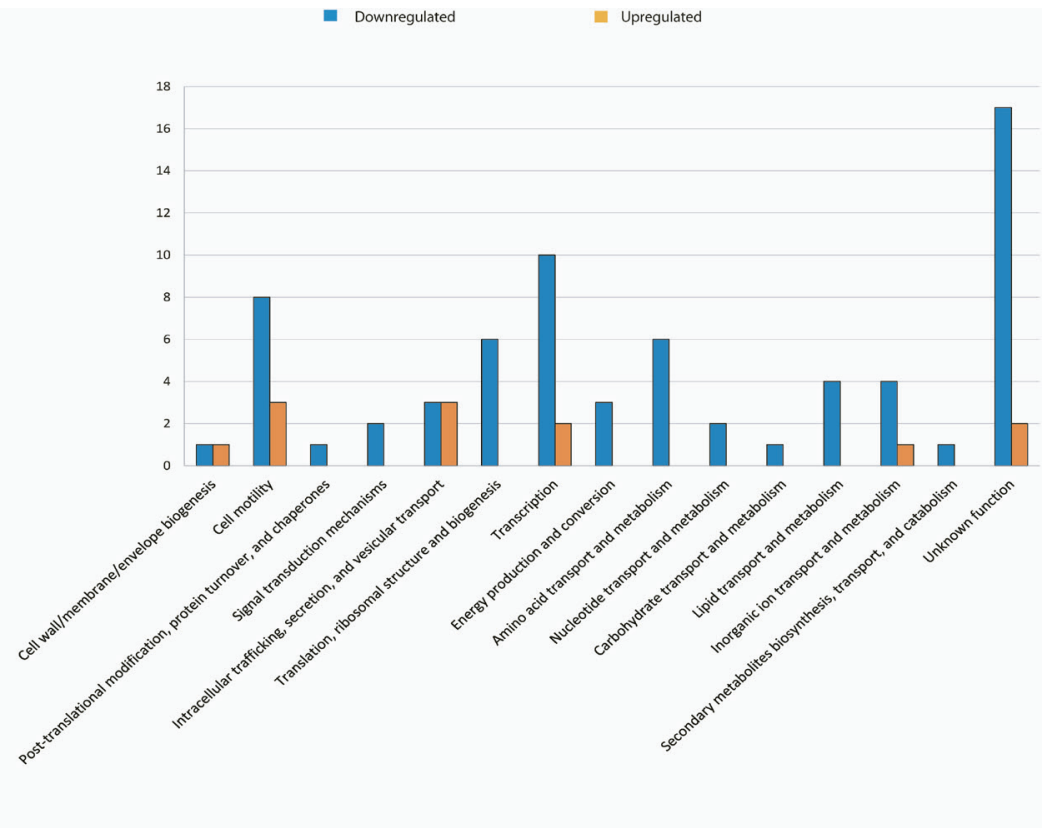

(B)

Fig. 1. Transcriptional response of S. maltophilia ATCC $13637^{\top}$ at $37^{\circ} \mathrm{C}$. (a) Volcano plot showing gene-expression profile of samples. The $Y$-axis represents $q$-values and $X$-axis represents $\log _{2}$ fold change values. The red dots represent significantly upregulated and downregulated genes with $\log _{2}$-fold change $(\geq 2$ or $\leq-2)$ and $q$-value $<0.05$. (b) COG-based classification of differentially expressed genes of S. maltophilia at $37^{\circ} \mathrm{C}$.

expressed genes belonging to the cell motility; secondary structure; post-translational modification; replication and repair; translation; lipid metabolism; coenzyme metabolism; nucleotide metabolism and transport; amino acid metabolism and transport classes were downregulated at $37^{\circ} \mathrm{C}$.
To partially validate the differentially expressed genes during growth at $37{ }^{\circ} \mathrm{C}$ as compared to at $28{ }^{\circ} \mathrm{C}$, we performed the qRT-PCR analysis of selected genes. We have analysed the expression profiles of 12 randomly selected differentially expressed genes at 37 and $28^{\circ} \mathrm{C}$ (Fig. 2). We have used $16 \mathrm{~S}$ rRNA and $f t s Z$ genes as an internal control.

Table 3. S. maltophilia ATCC $13637^{\top}$ genes significantly up-regulated during the growth at $37^{\circ} \mathrm{C}$ versus $28^{\circ} \mathrm{C}$

\begin{tabular}{|lccccc|}
\hline Locus tag & Gene description & Gene name & log $_{2}$-fold change & $\boldsymbol{P}$ value & $\boldsymbol{q}$-value \\
\hline DP16_RS07185 & VirB4 family type IV secretion/conjugal transfer ATPase & virB4 & 2.96759 & 0.00005 & 0.00022 \\
DP16_RS09460 & PAS sensor domain-containing protein and sulfite reductase subunit alpha & aer & 3.9106 & 0.00005 & 0.00022 \\
DP16_RS07200 & Type IV secretion protein & virB1 & 2.72586 & 0.00005 & 0.00022 \\
DP16_RS07180 & trbJ & trbJ & 2.64674 & 0.00005 & 0.00022 \\
DP16_RS07205 & P-type DNA transfer ATPase VirB11 & virB11 & 2.28306 & 0.00005 & 0.00022 \\
DP16_RS10420 & Transcriptional regulator, LacI family & fruR & 2.23076 & 0.00005 & 0.00022 \\
DP16_RS07175 & Type IV secretion protein & virB6 & 2.2604 & 0.00005 & 0.00022 \\
DP16_RS06915 & Cation transporter & MMT12 & 2.01605 & 0.00005 & 0.00022 \\
DP16_RS14080 & MULTISPECIES: type IV pilus modification protein PilV & PilV & 2.06625 & 0.0007 & 0.00241 \\
DP16_RS14085 & MULTISPECIES: Tfp pilus assembly protein FimT/FimU & Tfp & 2.14686 & 0.00135 & 0.00429 \\
DP16_RS07215 & MULTISPECIES: TrbG/VirB9 family P-type conjugative transfer protein & TrbG & 2.36236 & 0.00005 & 0.00022 \\
DP16_RS07195 & MULTISPECIES: TrbC/VirB2 family protein & TrbC & 2.76037 & 0.00005 & 0.00022 \\
\hline
\end{tabular}


Table 4. S. maltophilia ATCC $13637^{\top}$ genes significantly down-regulated during growth at $37^{\circ} \mathrm{C}$ versus $28^{\circ} \mathrm{C}$

\begin{tabular}{|c|c|c|c|c|c|}
\hline Locus tag & Gene description & Gene name & $\log _{2}$-fold change & $P$ value & $q$-value \\
\hline DP16_RS19070 & Fimbrial chaperone & fimB & -3.74341 & 0.00005 & 0.00022 \\
\hline DP16_RS01055 & Porin & - & -3.26817 & 0.00005 & 0.00022 \\
\hline DP16_RS03855 & Chemotaxis protein & $\mathrm{mcpU}$ & -2.60711 & 0.00005 & 0.00022 \\
\hline DP16_RS16150 & Polyketide cyclase & - & -2.46992 & 0.00005 & 0.00022 \\
\hline DP16_RS08430 & $\begin{array}{l}\text { beta-hydroxydecanoyl-ACP dehydratase/beta- } \\
\text { ketoacyl-[acyl-carrier-protein] synthase I }\end{array}$ & fabA, fabB & -2.81952 & 0.00005 & 0.00022 \\
\hline DP16_RS01020 & C4-dicarboxylate transporter & $\operatorname{dct} A$ & -2.31709 & 0.00005 & 0.00022 \\
\hline DP16_RS21325 & Methyl-accepting chemotaxis protein & $\mathrm{mcpU}$ & -2.31383 & 0.00005 & 0.00022 \\
\hline DP16_RS01805 & ATP synthase subunit B & atpF & -2.62816 & 0.00005 & 0.00022 \\
\hline DP16_RS12245 & Ribosome biogenesis GTPase Der & der & -2.23516 & 0.00005 & 0.00022 \\
\hline DP16_RS00260 & Peptidase M28 family protein & - & -2.16125 & 0.00005 & 0.00022 \\
\hline DP16_RS20730 & Peptidyl-prolyl cis-trans isomerase & sylDB & -2.49939 & 0.00005 & 0.00022 \\
\hline DP16_RS21125 & DsbA family oxidoreductase & frnE & -2.21017 & 0.00005 & 0.00022 \\
\hline DP16_RS17970 & Translational GTPase TypA & typA & -2.07728 & 0.00005 & 0.00022 \\
\hline DP16_RS04645 & Biopolymer transporter ExbB & exbB & -2.002 & 0.00005 & 0.00022 \\
\hline DP16_RS02840 & Dihydroorotate dehydrogenase & dtpA & -2.11169 & 0.00005 & 0.00022 \\
\hline DP16_RS09945 & $\mathrm{Mg}(2+)$ transport ATPase $\mathrm{C}$ & mgtC & -2.01719 & 0.00005 & 0.00022 \\
\hline DP16_RS16825 & BolA family transcriptional regulator & & -4.09326 & 0.00005 & 0.00022 \\
\hline DP16_RS06005 & Entericidin A/B family lipoprotein & & -4.0634 & 0.00005 & 0.00022 \\
\hline DP16_RS20940 & RidA family protein & & -3.23711 & 0.00005 & 0.00022 \\
\hline DP16_RS12470 & Preprotein translocase subunit YajC & yajC & -2.69781 & 0.00005 & 0.00022 \\
\hline DP16_RS19265 & Ferredoxin--NADP reductase & & -2.6871 & 0.00005 & 0.00022 \\
\hline DP16_RS21105 & Cold-shock protein & & -2.54197 & 0.00005 & 0.00022 \\
\hline DP16_RS11430 & $\begin{array}{l}\mathrm{AbrB} / \mathrm{MazE} / \mathrm{SpoVT} \text { family DNA-binding } \\
\text { domain-containing protein }\end{array}$ & & -2.53552 & 0.0001 & 0.00042 \\
\hline DP16_RS05720 & Sulphate transporter & & -2.53105 & 0.0011 & 0.0036 \\
\hline DP16_RS21940 & $\begin{array}{l}\text { YebC/PmpR family DNA-binding transcriptional } \\
\text { regulator }\end{array}$ & & -2.50375 & 0.00005 & 0.00022 \\
\hline
\end{tabular}


Table 4. Continued

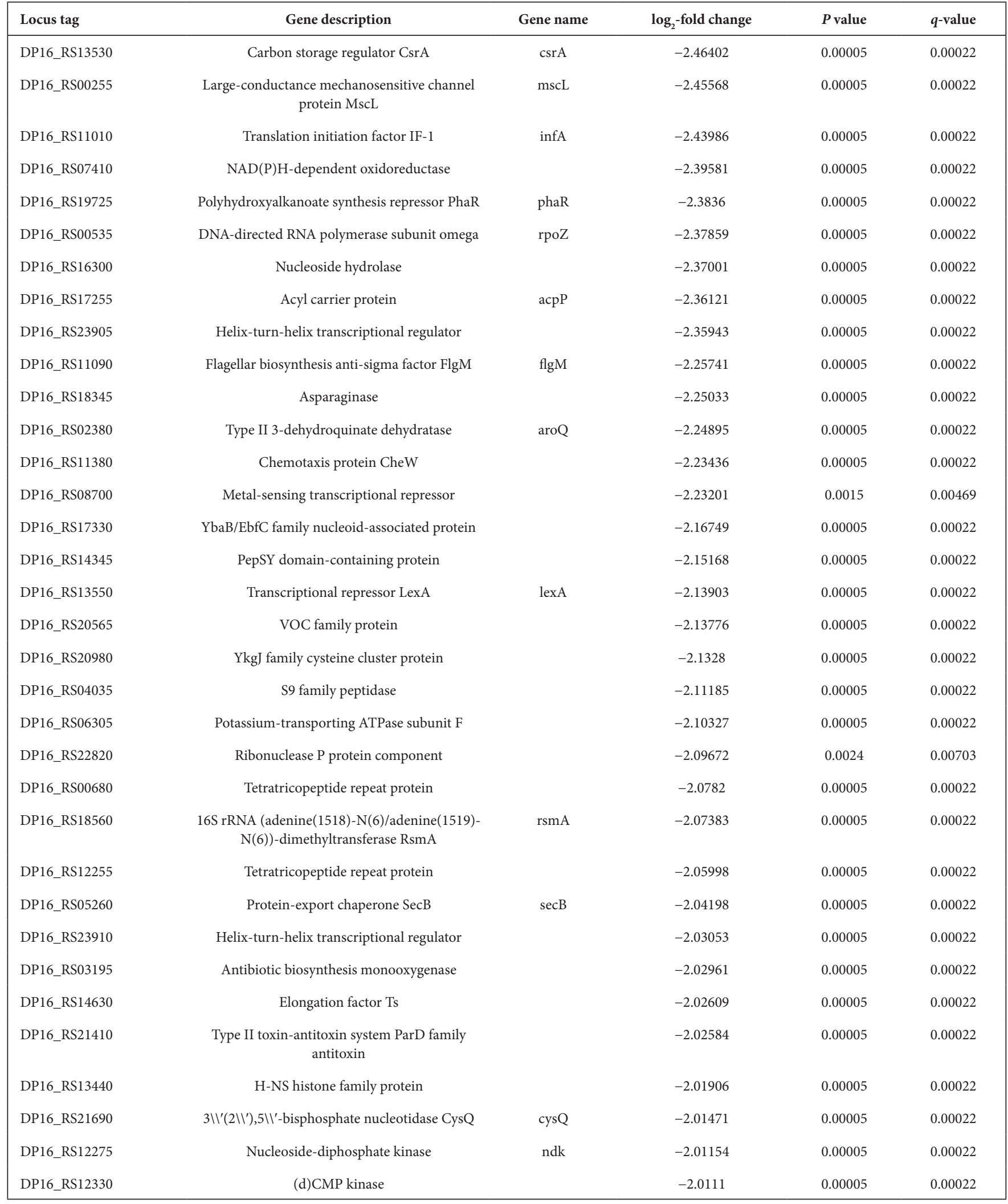




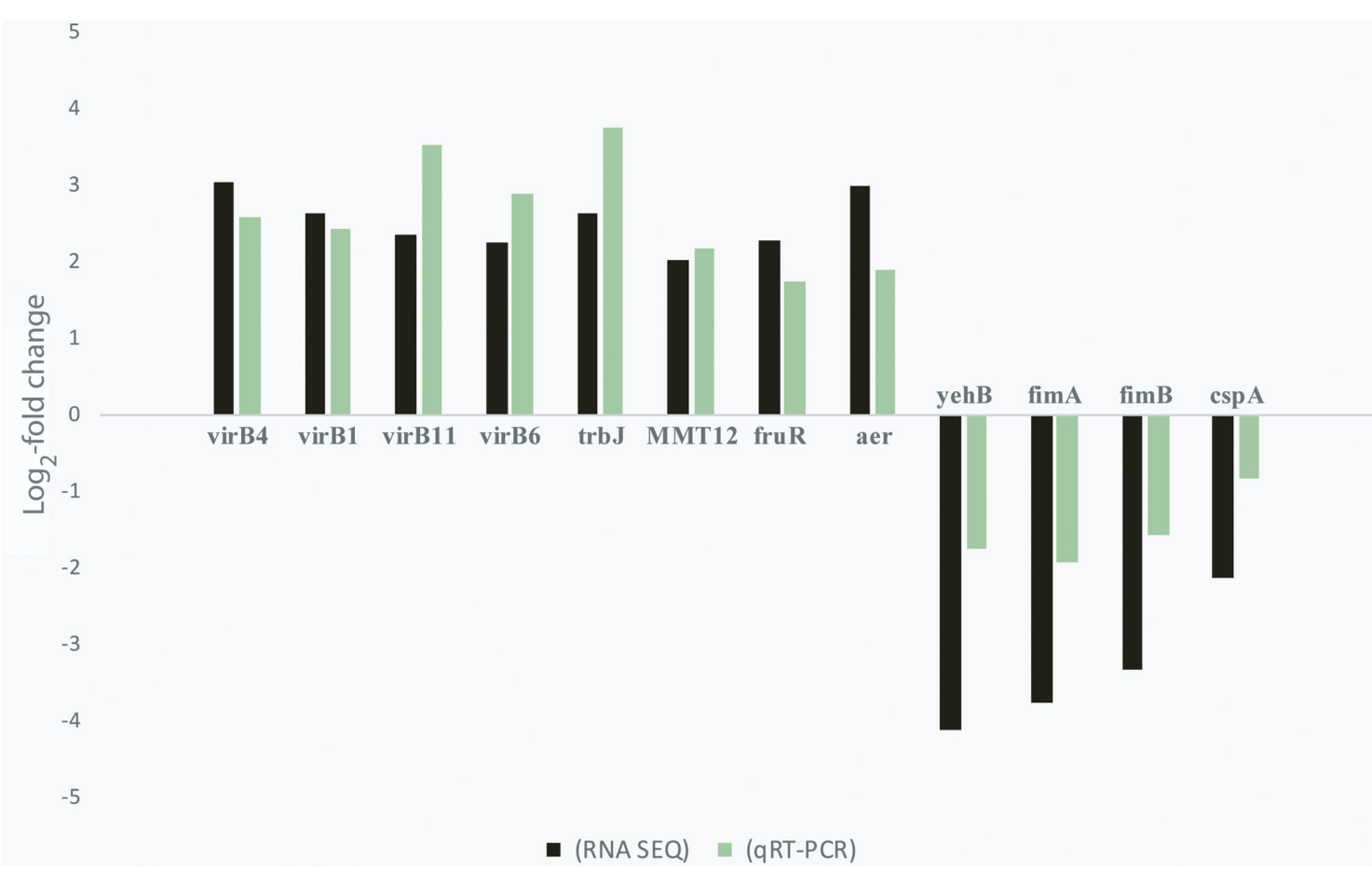

Fig. 2. qRT-PCR validation of differentially expressed genes. Expression profile of 12 genes by RNA-Seq and qRT-PCR.

High correlation $(\mathrm{R} 2=0.9135)$ between expression levels of genes measured by the RNA-Seq and qRT-PCR was observed (Fig. 2).

\section{Temperature-dependent regulation of cell motility}

The majority of the differentially expressed genes belong to the cell-motility category, and all of them were downregulated at $37^{\circ} \mathrm{C}$. These include isoforms of a gene (DP16_RS19060, DP16_RS19065), which encodes for fimbrial outermembrane protein and type I fimbrial proteins, fimbrial proteins (DP16_RS19075), fimbrial chaperone (DP16_ RS19070), methyl-accepting chemotaxis (DP16_RS03855), flagellin (DP16_RS11160), methyl-accepting chemotaxis protein (DP16_RS21325) and CheV chemotaxis protein (DP16_RS11100). The methyl-accepting chemotaxis proteins and $\mathrm{CheV}$ chemotaxis protein are categorized into signal transduction class along with GTP-binding protein TypA (DP16_RS17970), which were also downregulated (Table 4).

In order to check the phenotypic effect of downregulation of the cell motility and chemotaxis genes at $37^{\circ} \mathrm{C}$, we have performed the swimming and swarming motility assay during growth at 28 and $37^{\circ} \mathrm{C}$. The swimming and swarming motility is affected at $37^{\circ} \mathrm{C}$ as compared to that of $28{ }^{\circ} \mathrm{C}$ (Fig. 3a, b). Further, downregulation of genes involved in flagellin biosynthesis leads to the development of less or impaired flagella at $37^{\circ} \mathrm{C}$ as compared to the $28^{\circ} \mathrm{C}$, which was observed in transmission electron microscopy (Fig. 3c). The impaired flagella ultimately affect the motility at $37^{\circ} \mathrm{C}$ as compared to the $28^{\circ} \mathrm{C}$. Taken together, these observations suggest the thermoregulation of cell motility in S. maltophilia.

In bacterial pathogens, it is now a well-known fact that virulence-related traits are generally overexpressed at physiological temperature, i.e. $37^{\circ} \mathrm{C}$ [3]. The repression of motility genes at $37^{\circ} \mathrm{C}$ to avoid the host recognition was also reported in Listeria monocytogenes, which is a foodborne pathogen of environmental origin [29]. In Listeria monocytogenes, $\operatorname{mog} R$ transcriptional repressor of flagellar genes along with a protein thermometer $g m a R$, which represses flagellar biosynthesis at $37^{\circ} \mathrm{C}$. The temperaturedependent regulation of motility was observed in several human and plant pathogens like Yersinia enterocolitica, Listeria monocytogenes, Escherichia coli and Pseudomonas syringae [30-33].

The flagella and fimbriae serve as pattern recognition molecule (PAMP), which activate innate immune response in the host cell, thus acting as an essential virulence factor for S. maltophilia [34]. Despite the important role of flagellin and fimbria genes in the S. maltophilia pathogenesis, these genes were downregulated at $37^{\circ} \mathrm{C}$ suggesting that it is an adaptive mechanism by which $S$. maltophilia avoids host recognition and subsequent host innate immune response. In S. maltophilia FsnR is a canonical positive regulator directly or indirectly controlling the transcription of most flagellar genes by binding to the promoter region of the flagellar biosynthesis gene cluster [35]. There might be an involvement of the unidentified protein thermometer, 


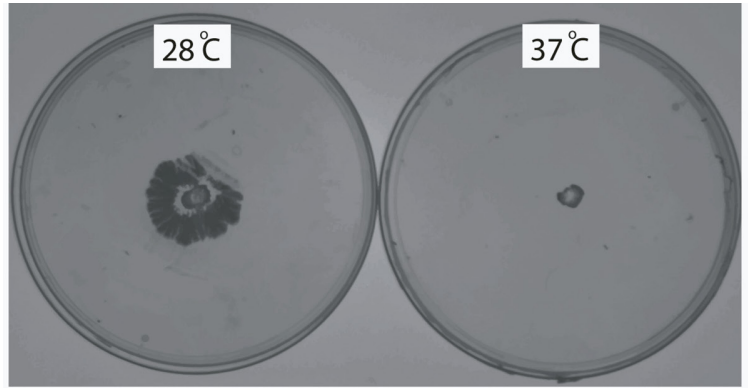

A. Twitching motility

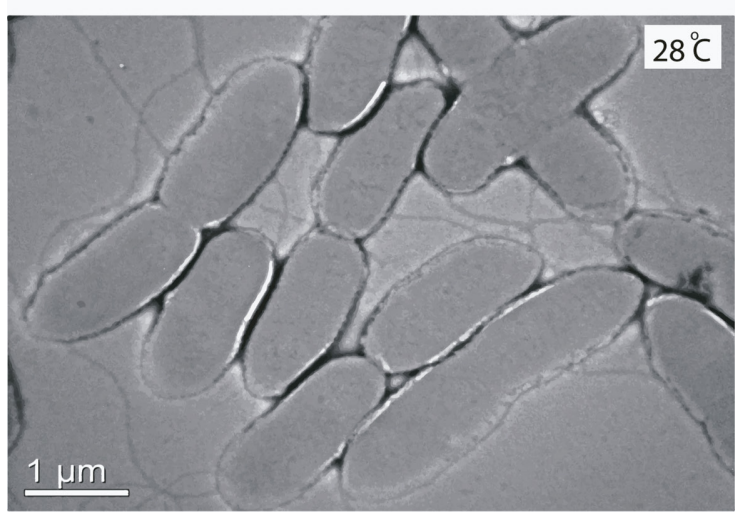

C. Transmission electron micrograph

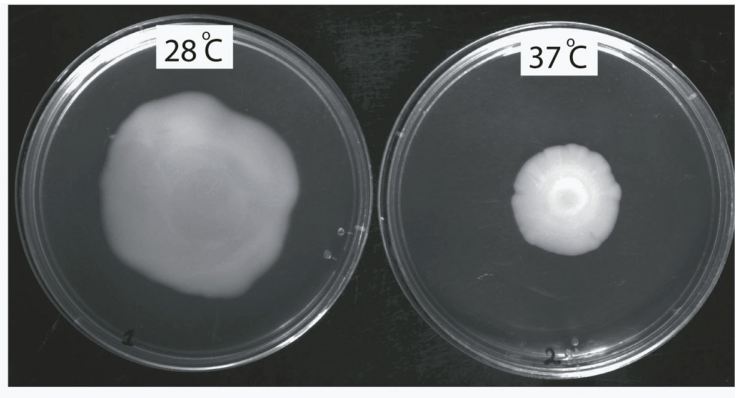

B. Swarming motility

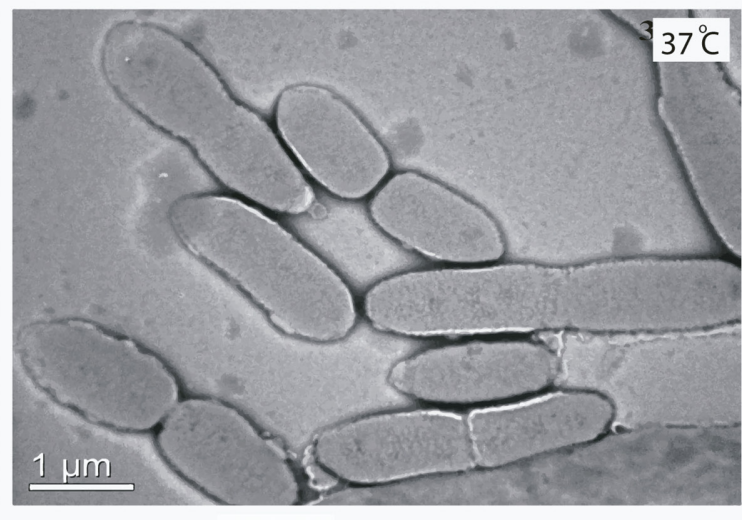

$1 \mu \mathrm{m}$

Fig. 3. Temperature-dependent regulation of motility. (a) Twitching motility of S. maltophilia ATCC $13637^{\top}$ observed during growth at 28 and $37^{\circ} \mathrm{C}$. (b) Swarming motility of S. maltophilia ATCC $13637^{\top}$ observed at growth 28 and $37^{\circ} \mathrm{C}$. (c) Transmission electron micrographs of S. maltophilia ATCC $13637^{\top}$ grown at 28 and $37^{\circ} \mathrm{C}$ on nutrient agar and negatively stained with $1 \%$ phosphotungstic acid.

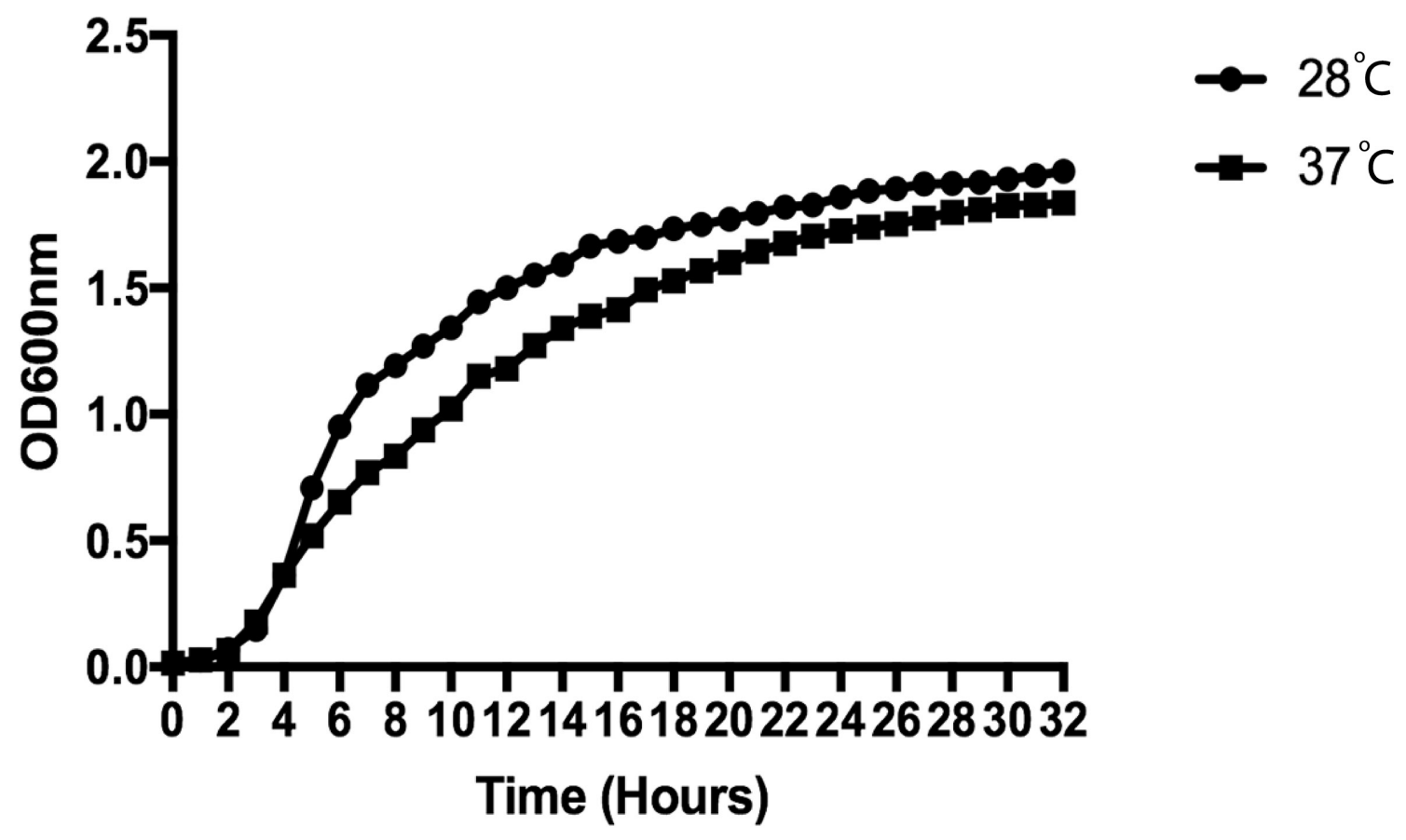

Fig. 4. Growth-curve measurement. Growth curve of S. maltophilia ATCC $13637^{\top}$ at two temperatures, i.e. 28 and $37^{\circ} \mathrm{C}$. 


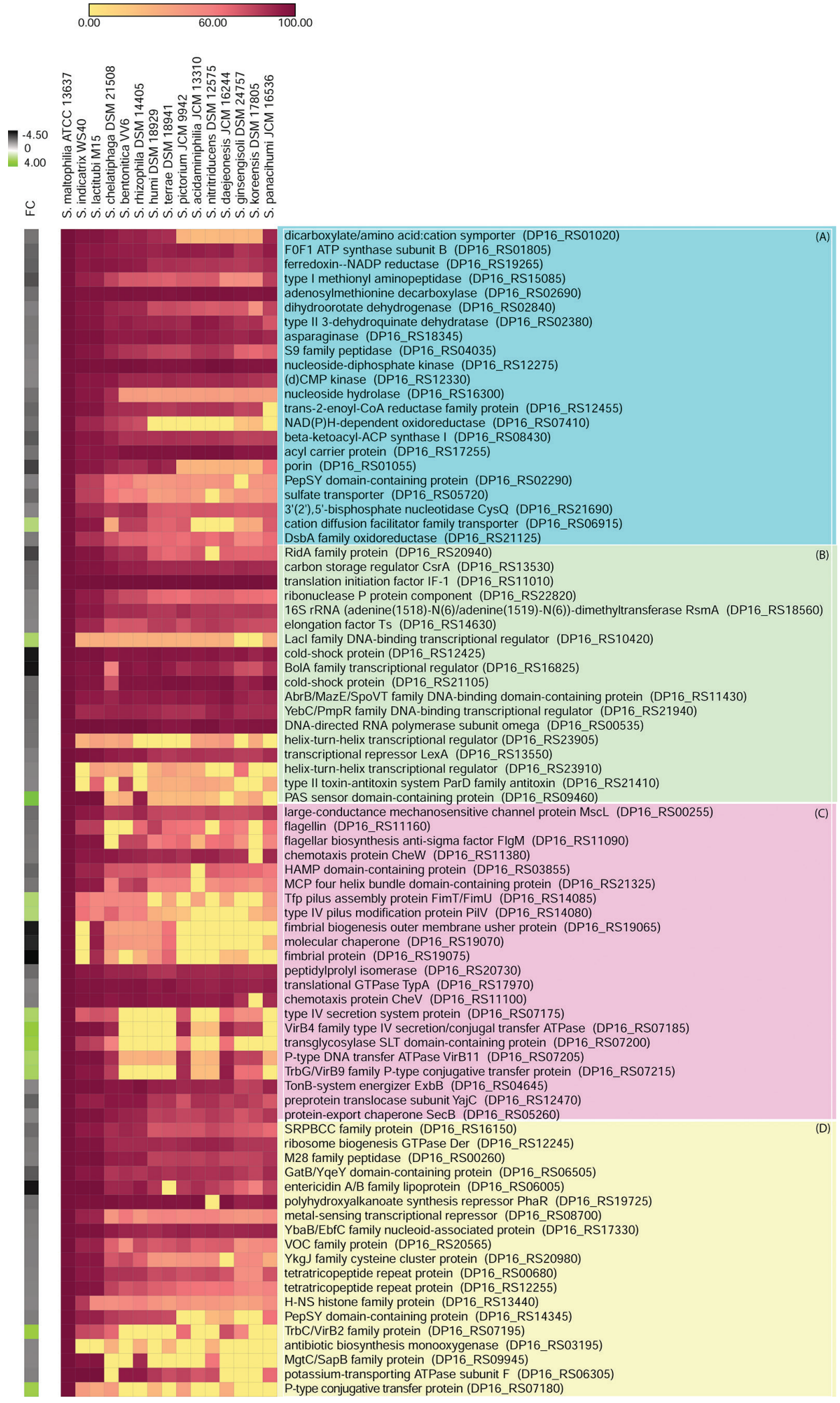

Fig. 5. Heatmap showing the presence or absence of differentially expressed genes in Smc along with $\log _{2}$-fold change of the genes at $37{ }^{\circ} \mathrm{C}$ as compared to $28{ }^{\circ} \mathrm{C}$. Genes related to (a) metabolism, (b) information storage and processing. (c) cellular processing and signalling, (d) others. 
which along with the FsnR may regulate the temperaturedependent flagellar motility. The chemotaxis involves selective movements by using flagella and pili towards nutrients or to escape from hostile environments. There is downregulation of the multiple key genes involved in chemotaxis, which is in accordance with the downregulation of the flagellin genes.

\section{Downregulation of genes involved in energy production, metabolism and protein synthesis}

The expression of two genes involved in energy production and conservation were downregulated at $37^{\circ} \mathrm{C}$. These include the ATP synthase subunit beta (DP16_RS01805) and C4-dicarboxylate transporter (DP16_RS01020) responsible for uptake of fumarate, succinate and malate, which are essential intermediates in TCA cycle. Apart from this, there is also downregulation of genes belonging to translation, amino acid metabolism and transport, replication and repair, inorganic ion and transport metabolism lipid metabolism, coenzyme metabolism was observed at $37^{\circ} \mathrm{C}$. Downregulated genes belong to inorganic ion transport and metabolism category, including phosphateselective porin O and P (DP16_RS01055), iron uptake factor (DP16_RS02290). The data suggested that downregulation of two genes involved in translation (DP16_RS15085), which encodes for a protein that removes the $\mathrm{N}$-terminal methionine from nascent proteins. The genes belonging to COG class: post-translational modification, protein turnover, chaperone functions DP16_RS20730 (peptidylprolyl cis-trans isomerase), nucleotide metabolism and transport, DP16_RS12245 (ribosome biogenesis GTPase), amino acid metabolism and transport, DP16_RS02690 (S-adenosylmethionine decarboxylase proenzyme), DP16_RS02840 (Dihydroorotate dehydrogenase), energy production and conversion DP16_RS01020 (sodium dicarboxylate symporter family), DP16_RS01805 (ATP synthase subunit B) were also downregulated. The downregulation of genes involved in energy production and metabolism; translation is reflected in the lower growth rate of $S$. maltophilia ATCC $13637^{\mathrm{T}}$ at $37^{\circ} \mathrm{C}$ as compared to $28^{\circ} \mathrm{C}$ (Fig. 4). This also suggests a reduction in energy production processes in S. maltophilia ATCC $13637^{\mathrm{T}}$ may represent a survival strategy during adaptation at human body temperature.

As S. maltophilia is an emerging nosocomial pathogen and not a 'professional pathogen', the effect of flagella may not be for infection purpose per se. For example, when it attaches equipment used in hospital settings and on patients and in biofilm form, downregulation of flagella and hence motility is expected and required. Similarly, other selective forces besides body temperature may be playing a role in altering the expression of genes in S. maltophilia. This can be seen in dry/high temperatures seen during summers and its lifestyle as soil/water in-habitant where temperature fluctuations are through the year. Hence such non-human-body-induced temperature changes may be counterproductive as seen in downregulated energy metabolism and may be one of the reasons for its status as an emerging and relatively less successful opportunistic human pathogens like Pseudomonas aeruginosa and Burkholderia cepacia complex.
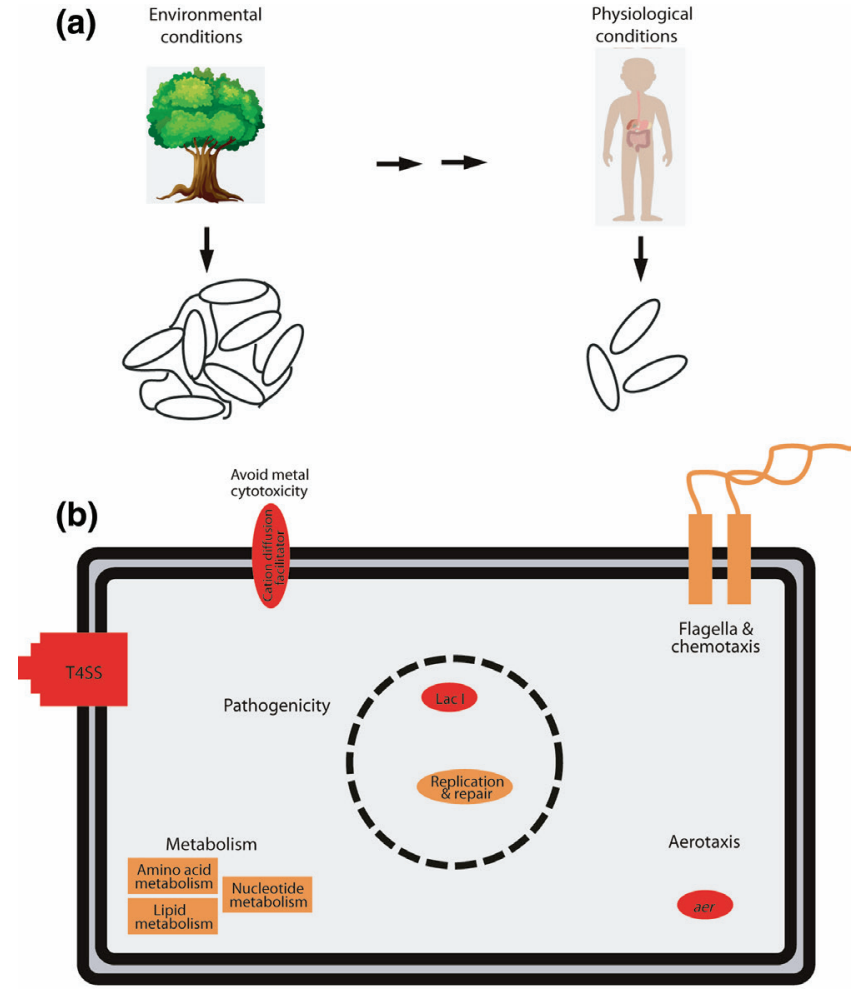

Fig. 6. (a) Transition of S. maltophilia from environment to clinical settings (b) Schematic diagram of upregulated (red) and downregulated (orange) genes.

\section{Upregulation of VirB/D4 type IV secretion system at $37^{\circ} \mathrm{C}$}

Comprehensive functional and COG analyses of upregulated genes revealed that five pivotal genes DP16_RS07185/virB4, DP16_RS07180/trbJ, DP16_RS07200/virB1, DP16 RS07205/virB11 and DP16_RS07175/virB6 that are part of the type IV VirB/D4 secretory system, were upregulated at $37^{\circ} \mathrm{C}$ (Table 3). The expression of the VirB/D4 T4SS components virB4, trbJ, virB1, virB11 and virB6 was higher at $37^{\circ} \mathrm{C}$ suggesting that VirB/D4 T4SS in S. maltophilia ATCC $13637^{\mathrm{T}}$ is regulated by the temperature. T4SS in S. maltophilia is horizontally acquired and present on the genomic island. It is present in the eight other non-clinical species of genus Stenotrophomonas, i.e. S. chelatiphaga, $S$. daejeonensis, S. ginsengisoli, S. indicatrix, S. koreensis, S. lactitubi, S. pavanii and S. pictorum [36]. The VirB/D4 T4SS is absent in the $S$. acidaminiphila, S. nitritireducens, S. panacihumi, S. rhizophila and S. terrae [36]. Apart from the role in conjugation, T4SSs also play an important role in the pathogenic mechanism of many animal pathogens Legionella pneumophila, Bordetella pertussis, Coxiella burnetii, Bartonella henselae, Brucella spp. and Helicobacter pylori as well as plant pathogen Agrobacterium tumefaciens $[37,38]$. VirB/D4 T4SS of S. maltophilia is related to the well-known plant pathogens of Xanthomonas species, a 
phylogenetic relative of $S$. maltophilia, which mediates killing of the other bacterial cell by T4SS but not involved in virulence [37]. In the latest study by Nas et al., they suggested that VirB/D4 T4SS in S. maltophilia inhibits the apoptosis in an epithelial cell to enhance attachment while it promotes apoptosis in infected mammalian macrophages to escape from phagocytosis [36]. The study further revealed that VirB/D4 T4SS in S. maltophilia stimulates the growth and mediates inter bacterial killing of other bacteria in the complex microbial community [36]. Thus, by considering the role of VirB/D4 T4SS in virulence, adaptation in the complex microbial community and its upregulation at $37^{\circ} \mathrm{C}$ suggests a temperature-dependent strategy for pathoadaptation.

\section{Upregulation of the genes involved in the aerotaxis, cation diffusion facilitator family transporter and Lacl family transcriptional regulators}

Interestingly, increased expression of genes involved in aerotaxis, which is also known as energy taxis at $37^{\circ} \mathrm{C}$. It is a behavioural response that guides bacterial cells to navigate toward microenvironments where oxygen concentration, energy sources and redox potential are optimal for growth [39]. This process is coordinated by aerotaxis receptor Aer, which measures redox potential. It infers energy levels via a flavin adenine dinucleotide (FAD) cofactor bound to a cytoplasmic PAS domain [39, 40]. In S. maltophilia ATCC $13637^{\mathrm{T}}$, two genes (DP16_RS09455 and DP16_RS09460) that encode for FAD-binding domain protein and PAS sensor domain-containing protein are transcribed as single transcript and are overexpressed at $37^{\circ} \mathrm{C}$. This may help S. maltophilia to adapt and colonize different niches with a different oxygen gradient. Thus, further experiments are required to understand the role of aerotaxis in S. maltophilia adaptation to human host and virulence. Reports are citing the role of aerotaxis in an adaptation of Campylobacter jejuni at human gut with different oxygen gradient and in Ralstonia solanacearum it is required for the biofilm formation [41, 42]. The role of the aerotaxis in virulence of bacteria is not fully understood, but it plays an important role in the adaptation of bacterium toward its host [43].

Among the upregulated gene, DP_RS06915, that code for cation diffusion facilitator (CDF) family transporter is important for the transition of metals efflux from the cytosol to periplasm. CDF transporter plays a role in the transition metal tolerance, i.e. exporting metal surplus from cell to avoid excessive accumulation and toxicity. Apart from the role in the transition metals efflux, they also participate in the infection process in $P$. aeruginosa [44]. As the transcription of CDF was increased at $37^{\circ} \mathrm{C}$ and by considering its possible role in the infection process, it is necessary to assess the role of CDF in virulence and adaption of S. maltophilia.

The transcription regulator of LacI family DP16_RS10420 is overexpressed at $37^{\circ} \mathrm{C}$. This family of transcriptional regulators is known to play an essential role in the carbohydrate uptake or metabolism and virulence [45-47]. Upregulation of the gene $f r u R$, which is a transcription factor and belongs to the LacI family was observed at $37^{\circ} \mathrm{C}$, suggesting it may play an important role in adaptation and virulence. Therefore, future studies are needed to reveal the role of these genes in infection and adaptation to human body temperature.

\section{Human body temperature is not heat stress for S. maltophilia}

The variation of temperature is considered as one of the important stress factors that induces bacterial heat-shock response to adapt and survive thermal stress conditions. Previous studies have reported the heat-induced changes in S. maltophilia including changes in the expression of various heat-shock proteins at higher temperature $\left(37^{\circ} \mathrm{C}\right)$ [48]. In our transcriptome study, we observed a significant downregulation of $\operatorname{csp} A 2$ gene that encodes for cold-shock protein at 37 ${ }^{\circ} \mathrm{C}$ suggesting its role in adaptation to lower environmental temperature. Despite the presence of heat-shock chaperons in S. maltophilia, we did not find differential gene expression of heat-shock response genes, which is generally indicative of heat stress. This suggests that $S$. maltophilia has evolved to thrive at human body temperature without a need to activate protective surveillance responses against heat stress. Overall, this emphasizes that human body temperature is not heat stress for S. maltophilia. This kind of response was also reported in the environmentally originated opportunistic pathogen Pseudomonas aeruginosa during growth at $37^{\circ} \mathrm{C}$ [2].

In an earlier study, De Carolis and co-workers reported upregulation of GroEL [48]. As the authors checked the expression of GroEL by RT PCR by giving heat shock to cells already growing at $27^{\circ} \mathrm{C}$ to high temperature unlike in our case where cells were separately grown at 28 and $37^{\circ} \mathrm{C}$. Further correlation between mRNA and protein expression can always vary due to various factors such as half-lives and post-transcription machinery. Hence the effect of experimental approaches and culture conditions need to be taken into account to understand regulation of genes and into its functional relevance.

Temperature is known to alter susceptibility in bacteria. In Escherichia coli, cold stress makes it susceptible to glycopeptide antibiotics [49], but in the case of S. maltophilia, higher temperature makes it susceptible to aminoglycosides [50]. In our study, the number of downregulated genes is far more than the number of upregulated genes, indicating temperaturedependent modulation of physiology, thereby affecting its success as an opportunistic pathogen. This corroborates with it being relatively less successful than its other nonfermenting Gram-negative bacilli (NFGN) pathogens like Pseudomonas aeruginosa and the Bcc complex. However, considering tremendous taxonogenomic diversity reported in the population of S. maltophilia $[9,51]$, it may, in its course of evolution, be the next major nosocomial pathogen.

In addition to clinical, $S$. maltophilia complexes have species from diverse lifestyles. Here, we looked for status of all the 81 pathoadaptive or differentially expressed genes status in all the species of Smc (Fig. 5). While, motility and T4SS genes 
in a few of the other species of genus Stenotrophomonas. Energy production, metabolism and transcription regulators are largely present in all the species of Smc. Overall phylogenomic-based transcritomic understanding reveals that the transistion and success of $S$. maltophilia species in the genus has been intricate by modulating functions related to immune evasion as seen by downregulation of flagella, protection from host defence responses as seen by downregulation of genes involved in motility apart from other cellular processes related to physiology, replication and transcription (Fig. 6). Further molecular genetic studies on the differentially expressed that are unique to $S$. maltophilia may allow the success of this species to be understood as an opportunistic human pathogen.

\section{CONCLUSION}

Current work is a high-resolution comprehensive comparative analysis of RNA-Seq based transcriptome of opportunistic pathogen S. maltophilia. This study has provided a framework for studying the molecular mechanism underlying transition of an environmental bacterium to become a successful human pathogen. The study also suggests how S. maltophilia is a matter of grave concern to the immunocompromised patient. Further, studies on the characterization of differentially expressed genes of S. maltophilia at physiological temperature will give more insights into its adaptation to human host and pathogenesis.

\section{Funding information}

This work is supported by CSIR funded project - MLP-016 project GEAR - Genomic, Evolutionary and Big Data Analytic strategies to address antimicrobial resistance. All authors declare no conflict of interests. P.P.P. is acknowledging Senior Research Fellowship from University Grant Commission, New Delhi. S.M. and S.K. fellowship from Council of Scientific and Industrial Research, India. A.K. is supported by Senior Research Fellowship from INSPIRE scheme of the Department of Sciences and technology, Government of India.

\section{Author contributions}

P.P.P., S.M., S.K. have prepared the RNA-Seq library preparation and performed transcriptome sequencing on Illumina MiSeq platform. P.P.P., S.K. and K.B. have performed computational analysis of RNA-Seq data analysis. P.P.P. and A.K. have performed motility assay, growth curve and validation of differentially expressed genes by RT-qPCR. A.K., S.K. and P.P.P. performed transmission electron microscopy (TEM). P.P.P. has drafted the manuscript with inputs from S.K., K.B. and A.K., P.B.P. and P.P.P. have conceived and designed the experiments with inputs from S.K., A.K. and K.B.

Conflicts of interest

The authors declare that there are no conflicts of interest.

\section{References}

1. White-Ziegler CA, Malhowski AJ, Young S. Human body temperature $\left(37^{\circ} \mathrm{C}\right)$ increases the expression of iron, carbohydrate, and amino acid utilization genes in Escherichia coli K-12. J Bacteriol 2007;189:5429-5440.

2. Wurtzel O, Yoder-Himes DR, Han K, Dandekar AA, Edelheit S, et al. The single-nucleotide resolution transcriptome of Pseudomonas aeruginosa grown in body temperature. PLoS Pathog 2012;8:e1002945.

3. Konkel ME, Tilly KJM. Temperature-regulated expression of bacterial virulence genes. Microbes Infect 2000;2:157-166.
4. Shapiro RS, Cowen LE. Thermal control of microbial development and virulence: Molecular mechanisms of microbial temperature sensing. mBio 2012;3.

5. Lam 0 , Wheeler J, Tang CM. Thermal control of virulence factors in bacteria: A hot topic. Virulence 2014;5:852-862.

6. Kortmann J, Narberhaus F. Bacterial RNA thermometers: Molecular zippers and switches. Nat Rev Microbiol 2012;10:255-265.

7. Weber M, Schünemann W, Fuß J, Kämpfer P, Lipski A. Stenotrophomonas lactitubi sp. nov. and Stenotrophomonas indicatrix sp. nov., isolated from surfaces with food contact. Int J Syst Evol Microbiol 2018;68:1830-1838.

8. Sánchez-Castro I, Ruiz-Fresneda MA, Bakkali $M$, Kämpfer $P$, Glaeser SP, et al. Stenotrophomonas bentonitica sp. Nov., isolated from bentonite formations. Int J Syst Evol Microbiol 2017;67:2779-2786.

9. Patil PP, Kumar S, Midha S, Gautam V, Patil PB. Taxonogenomics reveal multiple novel genomospecies associated with clinical isolates of Stenotrophomonas maltophilia. Microb Genom 2018;4.

10. Patil PP, Midha S, Kumar S, Patil PB. Genome sequence of type strains of genus Stenotrophomonas. Front Microbiol 2016;7:309.

11. Kaparullina E, Doronina N, Chistyakova T, Trotsenko Y. Stenotrophomonas chelatiphaga sp. nov., a new aerobic edta-degrading bacterium. Syst Appl Microbiol 2009;32:157-162.

12. Looney WJ, Narita M, Mühlemann K. Stenotrophomonas maltophilia: an emerging opportunist human pathogen. Lancet Infect Dis 2009:9:312-323.

13. Brooke JS. Stenotrophomonas maltophilia: an emerging global opportunistic pathogen. Clin Microbiol Rev 2012;25:2-41.

14. Brooke JS. New strategies against Stenotrophomonas maltophilia: a serious worldwide intrinsically drug-resistant opportunistic pathogen. Expert Rev Anti Infect Ther 2014;12:1-4.

15. Ryan RP, Monchy S, Cardinale M, Taghavi S, Crossman L, et al. The versatility and adaptation of bacteria from the genus Stenotrophomonas. Nat Rev Microbiol 2009;7:514-525.

16. Mukherjee P, Roy P. Genomic potential of Stenotrophomonas maltophilia in bioremediation with an assessment of its multifaceted role in our environment. Front Microbiol 2016;7:967.

17. Alavi P, Starcher MR, Thallinger GG, Zachow C, Müller H, et al. Stenotrophomonas comparative genomics reveals genes and functions that differentiate beneficial and pathogenic bacteria. BMC Genomics 2014:15:482.

18. Croucher NJ, Thomson NR. Studying bacterial transcriptomes using RNA-seq. Curr Opin Microbiol 2010;13:619-624.

19. Trapnell C, Hendrickson DG, Sauvageau M, Goff L, Rinn JL, et al. Differential analysis of gene regulation at transcript resolution with RNA-seq. Nat Biotechnol 2013;31:46-53.

20. Creecy JP, Conway T. Quantitative bacterial transcriptomics with RNA-seq. Curr Opin Microbiol 2015;23:133-140.

21. Andrews S. Fastqc: A quality control tool for high throughput sequence data. Version 0.11. 2. 2010, Babraham bioinformatics Cambridge UK. 2010.

22. Langmead B, Salzberg SL. Fast gapped-read alignment with Bowtie 2. Nat Methods 2012:9:357-359.

23. Li H, Handsaker B, Wysoker A, Fennell T, Ruan J, et al. The sequence Alignment/map format and samtools. Bioinformatics 2009:25:2078-2079.

24. Trapnell C, Williams BA, Pertea G, Mortazavi A, Kwan G, et al. Transcript assembly and quantification by RNA-seq reveals unannotated transcripts and isoform switching during cell differentiation. Nat Biotechnol 2010;28:511-515.

25. Trapnell C, Roberts A, Goff L, Pertea G, Kim D, et al. Differential gene and transcript expression analysis of RNA-SEQ experiments with tophat and cufflinks. Nat Protoc 2012;7:562-578.

26. Goff L, Trapnell C, Kelley D. cummerBund: Analysis, exploration, manipulation, and visualization of cufflinks high-throughput sequencing data. 2013;2. 
27. Huerta-Cepas J, Szklarczyk D, Forslund K, Cook H, Heller D, et al. Eggnog 4.5: A hierarchical orthology framework with improved functional annotations for eukaryotic, prokaryotic and viral sequences. Nucleic Acids Res 2016;44:D286-93.

28. Camacho C, Coulouris G, Avagyan V, Ma N, Papadopoulos J, et al. BLAST+: Architecture and applications. BMC Bioinformatics 2009;10:421.

29. Gründling A, Burrack LS, Bouwer HGA, Higgins DE. Listeria monocytogenes regulates flagellar motility gene expression through MOGR, a transcriptional repressor required for virulence. Proc Natl Acad Sci U S A 2004;101:12318-12323.

30. Kapatral V, Olson JW, Pepe JC, Miller VL, Minnich SA. Temperaturedependent regulation of Yersinia enterocolitica Class III flagellar genes. Mol Microbiol 1996;19:1061-1071.

31. Kamp HD, Higgins D. A protein thermometer controls temperaturedependent transcription of flagellar motility genes in Listeria monocytogenes. Plos Pathog 2011;7:e1002153.

32. Hockett KL, Burch AY, Lindow SE. Thermo-regulation of genes mediating motility and plant interactions in Pseudomonas syringae. PLoS One 2013;8:e59850.

33. Sciandrone B, Forti F, Perego S, Falchi F, Briani F. Temperaturedependent regulation of the Escherichia coli LPXT gene. Biochimica et Biophysica Acta (BBA) - Gene Regulatory Mechanisms 2019;1862:786-795

34. Zgair AK, Chhibber S. Stenotrophomonas maltophilia flagellin induces a compartmentalized innate immune response in mouse lung. J Med Microbiol 2010;59:913-919.

35. Kang XM, Wang FF, Zhang H, Zhang Q, Qiana W. Genome-wide identification of genes necessary for biofilm formation by nosocomial pathogen Stenotrophomonas maltophilia reveals that orphan response regulator fsnr is a critical modulator. Appl Environ Microbiol 2015;81:1200-1209.

36. Nas MY, White RC, DuMont AL, Lopez AE, Cianciotto NP. Stenotrophomonas maltophilia encodes a virb/vird4 type iv secretion system that modulates apoptosis in human cells and promotes competition against heterologous bacteria, including Pseudomonas aeruginosa. Infect Immun 2019;87.

37. Souza DP, Oka GU, Alvarez-Martinez CE, Bisson-Filho AW, Dunger G, et al. Bacterial killing via a type IV secretion system. Nat Commun 2015:6:1-9.

38. Gonzalez-Rivera C, Bhatty M, Christie P. Mechanism and function of type IV secretion during infection of the human host. Microbiol Spectr 2016;4
39. Taylor BL, Zhulin IB. PAS domains: Internal sensors of oxygen, redox potential, and light. Microbiol Mol Biol Rev 1999;63:479-506.

40. Campbell AJ, Watts KJ, Johnson MS, Taylor BL. Role of the F1 region in the Escherichia coli aerotaxis receptor aer. J Bacteriol 2011;193:358-366.

41. Hazeleger WC, Wouters JA, Rombouts FM, Abee T. Physiological activity of campylobacter jejuni far below the minimal growth temperature. Appl Environ Microbiol 1998;64:3917-3922.

42. Yao J, Allen $\mathrm{C}$. The plant pathogen Ralstonia solanacearum needs aerotaxis for normal biofilm formation and interactions with its tomato host. J Bacteriol 2007;189:6415-6424.

43. Henry JT, Crosson S. Ligand-binding PAS domains in a genomic, cellular, and structural context. Annu Rev Microbiol 2011;65:261-286.

44. Salusso A, Raimunda D. Defining the roles of the cation diffusion facilitators in Fe2+/Zn2+ Homeostasis and establishment of their participation in virulence in Pseudomonas aeruginosa. Front Cell Infect Microbiol 2017;7:84.

45. Van Gijsegem F, Wlodarczyk A, Cornu A, Reverchon S, HugouvieuxCotte-Pattat $\mathrm{N}$, et al. Analysis of the LACl family regulators of erwinia chrysanthemi 3937, involvement in the bacterial phytopathogenicity. MPMI 2008;21:1471-1481.

46. Njoroge JW, Nguyen Y, Curtis MM, Moreira CG, Sperandio V. Virulence meets metabolism: CRA and KDPE gene regulation in enterohemorrhagic Escherichia coli. mBio 2012;3:e00280-12.

47. Ravcheev DA, Khoroshkin MS, Laikova ON, Tsoy OV, Sernova NV, et al. Comparative genomics and evolution of regulons of the lacifamily transcription factors. Front Microbiol 2014;5:294.

48. De Carolis E, Posteraro B, Florio AR, Colonna B, Prosseda G, et al. Analysis of heat-induced changes in protein expression of Stenotrophomonas maltophilia K279a reveals a role for GroEL in the hosttemperature adaptation. Int J Med Microbiol 2011;301:273-281.

49. Stokes JM, French S, Ovchinnikova OG, Bouwman C, Whitfield C et al. Cold stress makes Escherichia coli susceptible to glycopeptide antibiotics by altering outer membrane integrity. Cell Chem Biol 2016;23:267-277.

50. Rahmati-Bahram A, Magee JT, Jackson SK. Temperature-dependent aminoglycoside resistance in Stenotrophomonas (Xanthomonas) maltophilia; alterations in protein and lipopolysaccharide with growth temperature. J Antimicrob Chemother 1996;37:665-676.

51. Gröschel MI, Meehan CJ, Barilar I, Diricks M, Gonzaga A, et al. The phylogenetic landscape and nosocomial spread of the multidrugresistant opportunist Stenotrophomonas maltophilia. Nat Commun 2020;11:2044.

\section{Five reasons to publish your next article with a Microbiology Society journal}

1. The Microbiology Society is a not-for-profit organization.

2. We offer fast and rigorous peer review - average time to first decision is 4-6 weeks.

3. Our journals have a global readership with subscriptions held in research institutions around the world.

4. $80 \%$ of our authors rate our submission process as 'excellent' or 'very good'.

5. Your article will be published on an interactive journal platform with advanced metrics.

Find out more and submit your article at microbiologyresearch.org. 